\title{
Hepatitis C virus and HIV co-infection among pregnant women in Rwanda
}

Mwumvaneza Mutagoma1*, Helene Balisanga', Dieudonné Sebuhoro', Aimable Mbituyumuremyi', Eric Remera', Samuel S. Malamba², David J. Riedel ${ }^{3}$ and Sabin Nsanzimana ${ }^{1}$

\begin{abstract}
Background: Hepatitis C virus (HCV) infection is a pandemic causing disease; more than 185 million people are infected worldwide. An HCV antibody (Ab) prevalence of $6.0 \%$ was estimated in Central African countries. The study aimed at providing HCV prevalence estimates among pregnant women in Rwanda.

Methods: HCV surveillance through antibody screening test among pregnant women attending antenatal clinics was performed in 30 HIV sentinel surveillance sites in Rwanda.

Results: Among 12,903 pregnant women tested at antenatal clinics, 335 (2.6\% [95\% Confidence Interval 2.32-2.87]) tested positive for HCV Ab. The prevalence of HCV Ab in women aged 25-49 years was $2.8 \%$ compared to $2.4 \%$ in women aged 15-24 years (aOR $=1.3$; [1.05-1.59]); This proportion was $2.7 \%$ [2.37-2.94] in pregnant women in engaged in non-salaried employment compared to $1.2 \%$ [0.24-2.14] in those engaged in salaried employment $(\mathrm{aOR}=3.2 ;$ [1.60-6.58]). The proportion of HCV Ab-positive co-infected with HIV was estimated at 3.9\% (13 cases). Women in urban residence were more likely to be associated with HCV-infection (OR $=1.3 ; 95 \% \mathrm{Cl}[1.0-1.6])$ compared to those living in rural setting.
\end{abstract}

Conclusion: HCV is a public health problem in pregnant women in Rwanda. Few pregnant women were co-infected with HCV and HIV. Living in urban setting was more likely to associate pregnant women with HCV infection.

Keywords: Hepatitis C virus, HIV, Pregnant women, HIV-HCV co-infection

\section{Background}

The global prevalence of hepatitis C virus (HCV) infection was estimated between 1.2 and $3.8 \%$ according to World Health Organization (WHO) Global Burden Disease (GBD), with more than 185 million people infected worldwide [1-4]. The region with the highest reported $\mathrm{HCV}$ prevalence in the world was found in Central Asia (3.8\%). In sub-Saharan Africa, the prevalence was $2.3 \%[1,5]$.

A study conducted in specific sub-Saharan African countries estimated a high prevalence of $\mathrm{HCV}(6.0 \%)$ in central African countries. In North Africa, Egypt has the highest HCV prevalence (17.5\%) followed by Morocco $(7.7 \%)[6,7]$.

In Rwanda, HCV seroprevalence studies have been limited to HIV- infected persons only [8,9]. A study

\footnotetext{
* Correspondence: mutagoma@gmail.com

${ }^{1}$ Rwanda Biomedical Center, Ministry of Health, P.O. Box: 7162, Kigali, Rwanda Full list of author information is available at the end of the article
}

conducted among adults in one HIV clinic in the capital, Kigali in 2010, showed that the prevalence of HCV antibody (anti-HCV) was 5.7\% [8]. The second found a sero-prevalence of $2.1 \%$ among HIV-infected persons in Rwanda [9].

Sexual and maternal to child transmission and household exposure are not listed among major factors of $\mathrm{HCV}$ transmission [2, 6]. The transmission of $\mathrm{HCV}$ from mother to child is estimated at $4-8 \%$, but the transmission rate increases to $17-25 \%$ if the mother is also HIV infected [10]. In sub-Saharan Africa the main factor of $\mathrm{HCV}$ prevalence is blood transfusions and unsterile injections [6].

The prevalence of $\mathrm{HCV}$ infection among pregnant women was estimated between 1 and $8 \%$ worldwide [11]. In the Arabian Peninsula and North African (Maghreb) region, $\mathrm{HCV}$ among pregnant women ranges from $8.6 \%$ in Egypt to less than 1\% in Libya [12]. In Nigeria, a study conducted among pregnant women, 
found that the prevalence of $\mathrm{HCV}$ ranged between 1.4\% for women aged between 20 and 35 years old and $11.1 \%$ for women aged less than 20 years old [13]. In a systematic review and meta-analysis study published in 2015, conducted in 21 sub-Saharan African countries, found that the overall $\mathrm{HCV}$ prevalence among pregnant women in antenatal clinic was $3 \%$ and was $2 \%$ in the Central African region [14].

The burden of HCV infection in the general population and among pregnant women is unknown in Rwanda. The objective of the current study in Rwanda was to determine the prevalence and factors associated with testing positive for anti-HCV among pregnant women attending antenatal care services.

\section{Methods}

\section{Study design}

In 2011, an HIV cross-sectional sero-surveillance activity included HCV antibody testing among other tests performed in pregnant women from June 2011 to December 2011. A signed informed consent was used.

\section{Setting and sites}

In Rwanda before 2005, only 24 sentinel sites participated in HIV surveillance. In order to be more representative, the number was increased to 30 sentinel sites in 2005 , with 14 located in urban areas and 16 in rural areas. Each province has at least two urban and two rural sites. Inclusion criteria for sites were: at least 80 new women enrolled for ANC services per month, geographically accessible, at least one midwife or a nurse experienced in maternity or ANC, and one laboratory technician. Hepatitis C screening was added in the 2011 survey.

\section{Sentinel population}

All pregnant women aged 15-49 years presenting for the first time for their current pregnancy for antenatal clinic and prevention of mother-to-child transmission (ANC-PMTCT) services during the data collection period and voluntarily agreeing to a venous blood draw for HIV and syphilis testing routine testing, were enrolled in the survey. Personal socio-demographic characteristics were collected using a surveillance form that was complete through interview conducted by trained data collectors who were also health center regular staff. The option of linking personal data was used to return hepatitis results to participants.

Women younger than 18 years were accompanied by an adult guardian and signed assent form to allow the participation in the survey. A sample size of 13,267 will result in a relative $10 \%$ precision around a point estimate (HIV prevalence) of $3 \%$ among pregnant women attending ANC at an alpha of 0.05 and power of 0.80 .

\section{Laboratory methods}

\section{Hepatitis C virus testing}

All hepatitis $\mathrm{C}$ screening tests were performed at the central level at the National Reference Laboratory (NRL) in Kigali. Hepatitis $\mathrm{C}$ antibody (HCV Ab) using Abbott ARCHITECT system included, Reagents, calibrator, control packs, Pre-Trigger Solution and Probe Conditioning Solution for the assays for screening for prior exposure to hepatitis $\mathrm{C}$ and/or current infection.

\section{HIV testing}

HIV testing was performed at the health facility on all eligible and consenting pregnant women samples using 3 rapid test algorithm in order to provide without delay HIV test result to participants for counseling and clinical management for HIV-positive according to the national testing guidelines.

For the survey quality assurance purpose, all positive and $10 \%$ of the negative were sent to NRL for retesting using ELISA-based HIV testing algorithm.

\section{Data collection}

Data collectors were selected among health facility staff. At each health facility, focal persons, including the Director and one laboratory technician, were selected to carry out data collection. Five-day training was organized to familiarize staff with the protocol, laboratory techniques related to the surveillance, and standard operating procedures (SOPs). Participants were consecutively enrolled according to the inclusion criteria until the determined sample size at the site was reached. A structured sero-surveillance questionnaire was administered to all eligible pregnant women attending ANC/PMTCT service. Forms were kept in a secure place at the sentinel sites and transported to the Rwanda Biomedical Center (RBC) after every 2 weeks during regular site supervision visits. Questionnaires and laboratory results were double-entered using Epi Info (CDC, Atlanta, GA) at RBC.

\section{Data analysis}

STATA software (StataCorp LP, 4905 Lakeway Drive, College Station, TX, USA) was used for data analysis. $\mathrm{HCV}$ prevalence, $\mathrm{HCV}$-HIV co-infection proportions and 95\% confidence limits were estimated separately by levels of socio-demographic factors. Bivariate logistic regression analysis was used to test for associations between screened $\mathrm{HCV}$ infection and potential risk factors. The multivariate analysis was performed to determine factors that were associated with $\mathrm{HCV}$ infection in the bivariate analysis at the $\leq 0.1$ significance level to develop the final multivariable model using a backward elimination method. All variables were modeled as categorical variables to check on potential interactions and associations. None of the 
tested interaction terms between age and marital status and age and education was significant. The prevalence of screened $\mathrm{HCV}$, among pregnant women was estimated at 95\% confidence intervals. The risk factors for HCV infection among pregnant women attending ANC services were determined from covariates fitted in the multivariable logistic regression analysis: age, marital status, education level, occupation, residence, parity and, HIV infection.

\section{Ethical considerations}

In 2011, blood specimen and interview-based data collection was only performed on volunteers eligible participants who provided informed consent. The survey was reviewed in accordance with CDC human subjects review procedures and was determined to be a non-research routine disease surveillance activity. The survey was approved by the Rwandan National Ethics Committee.

\section{Results}

Of, 13,292 pregnant women enrolled in the survey, $63.8 \%$ were 25 years old and above, $87.2 \%$ were married or cohabitating and $88.6 \%$ were illiterate. By source of income, $96.1 \%$ were not salaried. A proportion of $39.5 \%$ of women were at their $2-3$ parity, $30.7 \%$ were at their first parity. Among all pregnant women, 12,903 (97.1\%) were screened for HCV Ab, 335 (2.6\%) [95\%CI: 2.3-2.9] were identified $\mathrm{HCV}$ Ab-positive.

The prevalence of $\mathrm{HCV}$-screened positive was $2.4 \%$ [95\% CI: 1.6-3.2] among single pregnant women, $2.7 \%$ [95\% CI: 2.3-2.9] among married pregnant women, and $3.9 \%$ [95\% CI: 1.2-6.5] among separated, divorced or widowed pregnant women. The prevalence of $\mathrm{HCV}$ screened positive was higher in pregnant women with low education level (illiterate and primary education level) compared to those with high education level (secondary and university education level): 2.7\% [95\% CI: 2.4-3.0] for illiterate pregnant women or pregnant

Table 1 Hepatitis C virus and HIV co-infection among pregnant women attending ante-natal clinics in Rwanda, 2011

\begin{tabular}{|c|c|c|c|c|c|c|c|}
\hline \multirow[t]{2}{*}{ Characteristics } & \multirow{2}{*}{$\begin{array}{l}\text { Total } \\
\mathrm{N}\end{array}$} & \multicolumn{3}{|c|}{ Hepatitis C prevalence } & \multicolumn{3}{|c|}{ HIV co-infection proportion among HCV Ab- positive } \\
\hline & & $n$ & $\%$ & {$[95 \%$ C.I] } & $\mathrm{n}$ & $\%$ & {$[95 \%$ C.I] } \\
\hline \multicolumn{8}{|l|}{ Age group } \\
\hline $15-24$ & 4,669 & 109 & 2.3 & {$[1.91-2.77]$} & 1 & 0.9 & {$[-0.78-2.38]$} \\
\hline $25-49$ yrs & 8,160 & 226 & 2.8 & {$[2.41-3.13]$} & 12 & 5.3 & {$[1.76-6.19]$} \\
\hline \multicolumn{8}{|l|}{ Marital status } \\
\hline Single & 1,438 & 35 & 2.4 & {$[1.64-3.23]$} & 1 & 2.9 & {$[-1.94-5.78]$} \\
\hline Married/Cohabiting & 11,166 & 291 & 2.7 & {$[2.32-2.92]$} & 11 & 3.8 & {$[1.30-4.94]$} \\
\hline Divorced/Separated/Widow & 207 & 8 & 3.9 & {$[1.22-6.51]$} & 1 & 12.5 & {$[-5.47-15.47]$} \\
\hline \multicolumn{8}{|l|}{ Education } \\
\hline Illiterate/Primary & 11,319 & 305 & 2.7 & {$[2.40-2.99]$} & 12 & 3.9 & {$[1.40-4.99]$} \\
\hline Secondary/University & 1,468 & 26 & 1.8 & {$[1.96-2.45]$} & 1 & 3.8 & {$[-2.25-6.55]$} \\
\hline \multicolumn{8}{|l|}{ Employment } \\
\hline Salaried(Salaried employee + Housemaids) & 505 & 6 & 1.2 & {$[0.24-2.14]$} & 1 & 16.7 & {$[-26.18-59.60]$} \\
\hline Non-salaried & 12,268 & 326 & 2.7 & {$[2.37-2.94]$} & 12 & 3.7 & {$[1.27-4.49]$} \\
\hline \multicolumn{8}{|l|}{ Residence } \\
\hline Rural & 6,416 & 151 & 2.4 & {$[1.98-2.73]$} & 4 & 2.6 & {$[0.77-6.76]$} \\
\hline Urban & 6,487 & 184 & 2.8 & {$[2.43-3.25]$} & 9 & 4.9 & {$[1.17-4.75]$} \\
\hline \multicolumn{8}{|l|}{ Number of Pregnancies } \\
\hline 1 Pregnancy $^{a}$ & 3,886 & 100 & 2.6 & {$[2.75-3.72]$} & 0 & 0.0 & \\
\hline 2-3 pregnancies & 4,944 & 130 & 2.6 & {$[2.18-3.76]$} & 8 & 6.2 & {$[1.25-6.67]$} \\
\hline 4-5 pregnancies & 2,384 & 61 & 2.6 & {$[1.92-3.19]$} & 4 & 6.6 & {$[0.84-7.26]$} \\
\hline$>=6$ pregnancies & 1,356 & 38 & 2.8 & {$[1.92-3.68]$} & 1 & 2.6 & {$[-3.62-1.51]$} \\
\hline \multicolumn{8}{|l|}{ HIV status } \\
\hline Negative & 12,463 & 322 & 2.6 & {$[2.36-2.86]$} & - & - & - \\
\hline Positive & 429 & 13 & 3.0 & {$[1.42-4.66]$} & 13 & 100 & \\
\hline Total & 12,903 & 335 & 2.6 & {$[2.32-2.87]$} & 13 & 3.9 & {$[1.40-4.66]$} \\
\hline
\end{tabular}

ancluding the current one 
women with primary education level vs. $1.8 \%$ [95\%CI: 2.0-2.4 with secondary or university level]. Prevalence of $\mathrm{HCV}$-screened positive was higher among pregnant women in unsalaried employment compared to pregnant women in salaried employment with $2.7 \%$ [95\%CI: $2.4-3.0]$ and $1.2 \%$ [95\%CI: $0.2-2.1]$ respectively (Table 1)

HIV infection among HCV Ab positive was analyzed. Out of 335 screened HCV Ab-positive, 13 women were co-infected with HIV. The proportion of HIV infection among HCV-infected women was estimated at 3.9\% [95\% CI: 1.4-4.7]. This co-infection among HCV infected women varied in the different socio-demographic characteristics of pregnant women attending ANC (Table 1).

Education level, employment and residence were considered in determining factors associated with $\mathrm{HCV}$ infection (Table 2). In multivariate analysis, there is evidence that $\mathrm{HCV}$ among pregnant women was associated with urban residence with $\mathrm{aOR}=1.3$ [95\% CI: $1.0-1.6]$.

\section{Discussion}

All attendees to ANC services participated in the study and all consented for $\mathrm{HCV}$ testing. The overall prevalence of $\mathrm{HCV} \mathrm{Ab}$ screened positive among pregnant women in sentinel sites in Rwanda was estimated at $2.6 \%$. Due to insufficient blood sample, $2.9 \%$ of participants were not tested for HCV. Pregnant women aged between 25 and 49 years were more likely to be infected with $\mathrm{HCV}$ than younger pregnant women (15-24 years old). The proportion of HIV-positive among HCV Abpositive pregnant women in ANC sentinel surveillance sites was $(3.9 \%)$.

The HCV prevalence among pregnant women in sentinel sites in Rwanda was similar to the overall HCV prevalence in sub-Sahara African countries (3.0\%) and the prevalence of $\mathrm{HCV}$ in Central African region (2.0\%) [13]. It was also similar to the prevalence using confirmed HCV-positive tests in Malawi (2.0\%) [15], and higher than the HCV prevalence among pregnant women in Brazil, United Kingdom (London) and Nigeria

Table 2 Hepatitis C Virus infection associated factors among pregnant women attending ante-natal clinics in Rwanda, 2011

\begin{tabular}{|c|c|c|c|c|c|c|}
\hline & \multicolumn{3}{|c|}{ Bivariate } & \multicolumn{3}{|c|}{ Multivariable } \\
\hline & $\mathrm{COR}$ & $p$-value & {$[95 \% \mathrm{Cl}]$} & $\overline{\mathrm{aOR}}$ & $p$-value & {$[95 \% \mathrm{Cl}]$} \\
\hline \multicolumn{7}{|l|}{ Age group } \\
\hline \multicolumn{7}{|l|}{$15-24$ years } \\
\hline $25-49$ years & 1.19 & 0.14 & {$[0.95,1.50]$} & - & & \\
\hline \multicolumn{7}{|l|}{ Education } \\
\hline \multicolumn{7}{|l|}{ Illiterate/primary } \\
\hline Secondary/University & 0.65 & 0.04 & {$[0.43,0.98]$} & 0.69 & 0.10 & {$[0.45,1.07]$} \\
\hline \multicolumn{7}{|l|}{ Marital status } \\
\hline \multicolumn{7}{|l|}{ Single } \\
\hline Married/cohabiting & 1.07 & 0.70 & {$[0.75,1.53]$} & - & & \\
\hline Divorced/Separated/Widow & 1.61 & 0.23 & {$[0.74,3.52]$} & - & & \\
\hline \multicolumn{7}{|l|}{ Employment } \\
\hline \multicolumn{7}{|l|}{ Salaried } \\
\hline Non-salaried & & 0.04 & {$[1.00,5.12]$} & 1.87 & 0.15 & {$[0.80,4.40]$} \\
\hline \multicolumn{7}{|l|}{ Residence } \\
\hline \multicolumn{7}{|l|}{ Rural } \\
\hline Urban & 1.21 & 0.09 & {$[0.97,1.51]$} & 1.28 & 0.03 & {$[1.02,1.60]$} \\
\hline \multicolumn{7}{|l|}{ Pregnancies } \\
\hline \multicolumn{7}{|l|}{1 Pregnancy } \\
\hline 2-3 pregnancies & 1.02 & 0.87 & {$[0.79,1.33]$} & - & & \\
\hline 4-5 Pregnancies & 0.99 & 0.97 & {$[0.72,1.37]$} & - & & \\
\hline$>=6$ Pregnancies & 1.09 & 0.65 & {$[0.75,1.59]$} & - & & \\
\hline \multicolumn{7}{|l|}{ HIV status } \\
\hline \multicolumn{7}{|l|}{ Negative } \\
\hline Positive & 1.18 & 0.57 & {$[0.67,2.07]$} & - & & \\
\hline
\end{tabular}


of $0.2,0.8$ and $1.5 \%$ respectively $[12,15]$. In the African region, the prevalence of $\mathrm{HCV}$ in the general population widely varied by country, ranging from 0.1 to $17.5 \%$ [7]. The increase of HCV with age was observed in a study conducted in Brazil among pregnant women in 2009 [16] and in all African regions [9]. A study of a global epidemiology of hepatitis $C$ virus infection found that $\mathrm{HCV}$ prevalence increased with age with different $\mathrm{HCV}$ prevalence peak in different ages in different regions [1]. The HCV and HIV co-infection proportion among pregnant women attending the ANC services in Rwanda was $3.9 \%$.

The HCV and HIV co-infection was low among $\mathrm{HCV}$-positive pregnant women in Rwanda. The proportion of the co-infection was lower compared to published studies in sub-Sahara countries (16.0\%) and in Central African region (6.0\%). A Brazilian study published in 2009 reported $7.0 \%$ of HCV-positive pregnant women were co-infected with HIV-1 [15]. In European countries, among HIV-positive enrolled pregnant women this co-infection was very high (12.3\%) [17]. In 2010, a meta-analysis [15] focusing on $\mathrm{HIV}$ and HCV co-infection using published studies in consecutive years from several sub-Saharan African countries for adult people published the following results: In $2006 \mathrm{HCV}$ and HIV co-infection was $4.8 \%$ in Burkina Faso and in 2007, it was $8.6 \%$ in Cameroon. In $2008 \mathrm{HCV}$ and HIV co-infection in Ethiopia was $1.8 \% ; 1.8 \%$ in Kenya, $1.1 \%$ in Malawi, $15.7 \%$ in Mozambique, $8.0 \%$ in Senegal, $13.4 \%$ in South Africa and $18.1 \%$ in Tanzania. In another study, it was reported that HCV and HIV co-infection in Nigeria was $3.8 \%$ in 2009 [14].

A significant difference in odds of having $\mathrm{HCV}$ was observed among pregnant women in urban residence compared to rural residence. That is, the HCV risk was higher in the urban than the rural women. The assumption behind this situation is the usual location of key population in urban setting than in rural ones.

In our study, there was no evidence to suggest a significant association between HIV and HCV infections. Similar observations were made in a study conducted in Kigali among adult HIV-positive persons [8].

The co-infection of HIV and HCV is associated with high mortality due to liver diseases compared to mono-infection [18]. Therefore, HIV is considered an important risk factor for $\mathrm{HCV}$ in the general population but has not been widely investigated. Most published studies on HCV risk factors were conducted among high-risk groups such as sex workers, injecting drug users and men who have sex with men and blood transfusion $[2,6]$.

This study had several limitations, namely: The survey was part of the antenatal sentinel sites sero-surveillance and therefore findings are applied to pregnant women in sentinel sites and cannot be generalized to the whole population in Rwanda or to pregnant women in other sub-Saharan African countries. Secondly, due to the small number of $\mathrm{HCV}$ and HIV co-infected pregnant women in our survey, it was not possible to assess the magnitude of this co-infection in selected socio-demographic characteristics sub-groups. Thirdly, in the present survey, Abbott ARCHITECT system is a screening test with high sensitivity. Therefore, in the context of our study, this screening test that was originally used in blood transfusion services to minimize hepatitis $\mathrm{C}$ transmission from blood donors; we may have some false $\mathrm{HCV}$ Ab-positive results.

\section{Conclusion}

$\mathrm{HCV}$-infection is a public health burden among pregnant women in Rwanda. This study provides a platform to inform policymakers and stakeholders the need to accelerate progress in treatment access and global prevention of $\mathrm{HCV}$ infections.

Further advanced studies of HCV in this group and in the general population are needed to explore detection of Antigens and Antibodies and how they inform the diagnosis of acute and active HCV infections.

\section{Abbreviations}

Ab: Antibody; AIDS: Acquired Immunodeficiency Syndrome; ANC: Antenatal care; aOR: Adjusted Odds Ratio; CDC: Centre for disease control and prevention; Cl: Confidence interval; ELISA: Enzyme-Linked Immuno-Sorbent Assay; GBD: Global Burden Disease; HBV: Hepatitis B Virus; HCV: Hepatitis C Virus; HIV: Human immunodeficiency virus; NRL: National Reference Laboratory; OR: Odds ratio; PEPFAR: President's Emergency Plan for AIDS Relief; PMTCT: Prevention of mother to child transmission; RBC: Rwanda Biomedical Center; SOPs: Standard Operating Procedures; WHO: World Health Organization

\section{Acknowledgement}

We acknowledge the contribution of the United States Center for Disease Control and Prevention, World Health Organization, the Government of Rwanda and other partners for their financial and technical support. We are recognizing the Blood Borne Infections technical working group, participants in the survey and sentinel site staff for their kind collaboration.

\section{Funding}

The survey was funded by the Government of Rwanda, CDC and WHO

\section{Availability of data and materials}

The dataset and materials source of the current paper are not publically available, but are available from the Rwanda Biomedical Center on reasonable request.

\section{Authors' contributions}

MM had full access to all of the data in the study. MM takes responsibility for the integrity of the data, the accuracy of the data analysis, and the final decision to submit for publication. MM, HB and SN contributed to study concept, design and data collection; MM and HB supervised data collection; MM, DS, ER and SSM performed statistical analysis; all authors contributed to data review and interpretation. MM and AM drafted the manuscript; SSM and DJR conducted a critical revision of the manuscript for important intellectual content. SN, MM, HB contributed to fund mobilization, administrative and technical support. All authors read and approved the final manuscript. 


\section{Competing interests}

The authors declare that they have no competing interests.

\section{Consent for publication}

The publication of the current data in peer review is in common agreement from all authors.

\section{Ethics approval and consent to participate}

The survey was reviewed and approved by CDC and the Rwandan National Ethics Committee. All participants signed informed consent form before to be enrolled in the survey and agreed with publication of the findings.

\section{Disclaimer}

This project has been supported by the President's Emergency Plan for AIDS Relief (PEPFAR) through the Centers for Disease Control and Prevention (CDC) under the terms of a Cooperative Agreement Number COAG\# 5 U2GPS002048.

The findings in this paper are those of the authors and do not necessarily represent the views of their supporting institutions.

\section{Author details}

${ }^{1}$ Rwanda Biomedical Center, Ministry of Health, P.O. Box: 7162, Kigali, Rwanda. ${ }^{2}$ US Centers for Disease Control and Prevention (CDC), Center for Global Health (CGH), Division of Global HIV/AIDS (DGHA), Kigali, Rwanda. ${ }^{3}$ Institute of Human Virology and Division of Infectious Diseases, University of Maryland School of Medicine, Baltimore, MD, USA.

Received: 27 August 2016 Accepted: 17 February 2017

Published online: 22 February 2017

\section{References}

1. Khayriyyah MH, Groeger JU, Flaxman AD, et al. Global epidemiology of hepatitis C virus infection: New estimates of Age-specific antibody to HCV seroprevalence. Hepatology. 2013;57(4):1333-42.

2. Tatiana M, Narciso-Schiavon JL, Schiavon SL, et al. Epidemiology of hepatitis C virus infection. Rev Assoc Med Bras. 2011;57(1):105-10.

3. Shepard CW, Finelli L, Alter MJ. Global epidemiology of hepatitis C virus infection. Lancet Infect Dis. 2005;5:524-6.

4. Gray RR, Salemi M, Klenerman P, Pybus OG. A New evolutionary model for hepatitis C virus chronic infection. PLoS Pathog. 2012;8(5):e1002656. doi:10.1371/journal.ppat.1002656.

5. Alter MJ. Epidemiology of hepatitis C virus infection. World J Gastroenterol. 2007;13(17):2436-41.

6. Madhava V, Burgess C, Drucker E. Epidemiology of chronic hepatitis C virus infection in sub-Saharan Africa. Lancet Infect Dis. 2002;2:293-302.

7. Karoney MJ, Siika AM. Hepatitis C virus (HCV) infection in Africa: a review. Pan Afr Med J. 2013;14:44. doi:10.11604/pamj.2013.14.44.2199.

8. Rusine J, Ondoa P, Asiimwe-Kateera B, Boer KR, Uwimana JM, et al. High Seroprevalence of HBV and HCV Infection in HIV-Infected Adults in Kigali, Rwanda. PLoS One. 2013;8(5):e63303. doi:10.1371/journal.pone.0063303.

9. World Health Organization. Guidelines for the screening, care and treatment of persons with hepatitis C infection. 2014.

10. Arshad M, El-Kamary SS, Jhaveri R. Hepatitis C virus infection during pregnancy and the newborn period. J Viral Hepat. 2011;18(4):229-36.

11. Gasim I, Murad IA, Ishag A. Hepatitis B and C virus infections among pregnant women in Arab and African countries. J Infect Dev Ctries. 2013;7(8):566-78

12. Chukwujekwu EO, Kalejaiye OO, Chidinma V, Gab-Okafor et al. Seroprevalence and factors associated with Hepatitis B and C co-infection in pregnant Nigerian women living with HIV Infection. doi:10.11604/pamj.2014. 17.197.2310

13. Bhargavi VR, Johari $N$, du Cros $P$, et al. Hepatitis $C$ seroprevalence and HIV co-infection in sub-Saharan Africa: a systematic review and meta-analysis. Lancet Infect Dis. 2015:15:819-24.

14. Barth RE, Huijgen Q, Taljaard J, et al. Hepatitis B/C and HIV in sub-Saharan Africa: an association between highly prevalent infectious diseases. A systematic review and meta-analysis. Int J Infect Dis. 2010;14:e1024-31.

15. Ward C, Tudor-Williams G, Cotzias T, Hargreaves S, Regan L, Foster GR. Prevalence of hepatitis $C$ among pregnant women attending an inner London obstetric department: uptake and acceptability of named antenatal testing. Gut. 2000;47:277-80.
16. Costa ZB, Machado GC, Avelino MM, et al. Prevalence and risk factors for Hepatitis C and HIV-1 infections among pregnant women in Central Brazil. BMC Infect Dis. 2009;9:116.

17. Landes $M$, Newell ML, Barlow $P$, et al. Hepatitis B or hepatitis C coinfection in HIV-infected pregnant women in Europe. HIV Med. 2008;9:526-34.

18. Rotman $Y$, Liang TJ. Coinfection with hepatitis $C$ virus and human immunodeficiency virus: virological, immunological, and clinical outcomes. J Virol. 2009:83(15):7366. doi:10.1128/JVI.00191-09.

\section{Submit your next manuscript to BioMed Central and we will help you at every step:}

- We accept pre-submission inquiries

- Our selector tool helps you to find the most relevant journal

- We provide round the clock customer support

- Convenient online submission

- Thorough peer review

- Inclusion in PubMed and all major indexing services

- Maximum visibility for your research

Submit your manuscript at www.biomedcentral.com/submit
Biomed Central 